\title{
Acute Kidney Injury in Pediatric Treated with Vancomycin and Piperacillin-Tazobactam in Tertiary Care Hospital
}

\author{
Mohammed Al Nuhait $\mathbb{D}^{1,2}$ Laila C. Abu Esba, ${ }^{1,2}$ Khalid Al Harbi, \\ Meshary Al Meshary, ${ }^{1}$ and Rami T. Bustami ${ }^{2}$ \\ ${ }^{1}$ King Abdulaziz Medical City, Pharmaceutical Care Services, Ministry of National Guard Health Affairs, Riyadh, Saudi Arabia \\ ${ }^{2}$ College of Pharmacy, King Saud Bin Abdul-Aziz University for Health Sciences (KSAU-HS), Ministry of National Guard \\ Health Affairs, Riyadh, Saudi Arabia \\ ${ }^{3}$ Prince Sultan Military Medical City, Department of Pharmacy, Riyadh, Saudi Arabia
}

Correspondence should be addressed to Mohammed Al Nuhait; alnuhaitmo@ngha.med.sa

Received 18 July 2018; Accepted 21 November 2018; Published 16 December 2018

Academic Editor: Hans Juergen Laws

Copyright (C) 2018 Mohammed Al Nuhait et al. This is an open access article distributed under the Creative Commons Attribution License, which permits unrestricted use, distribution, and reproduction in any medium, provided the original work is properly cited.

\begin{abstract}
Background. Vancomycin and piperacillin-tazobactam (PTZ) are commonly used as empirical therapy for patients with health care associated infections. Vancomycin has been recognized as a nephrotoxic agent and in a few cases in the literature PTZ has been associated with interstitial nephritis nevertheless; the combination of these agents has routinely been used for many years. However, there have been some observational studies that showed high rates of acute kidney injury (AKI) in patients receiving vancomycin and PTZ concomitant treatment compared to patients receiving vancomycin alone. The incidence of AKI in adult patients receiving vancomycin and PTZ concomitant treatment was reported in these studies to be relatively high. Similar studies in pediatric patients are lacking. Method. We conducted a single center retrospective chart review of 248 pediatric patients receiving one of the following treatments: vancomycin alone 36 patients, vancomycin/PTZ 62 patients, vancomycin/ceftazidime 99 patients, and vancomycin/ceftriaxone 51 patients. Result. Our results showed a low incidence of AKI in patients on vancomycin/PTZ concomitant treatment where overall incidence was only $(4.8 \%)$ three cases and only one of them (2.0\%) in a patient receiving the vancomycin/ceftriaxone concomitant treatment. No cases of AKI present in patients receiving vancomycin with ceftazidime or vancomycin alone. There were no statistically significant differences between the four treatment groups in terms of AKI incidence, vancomycin trough, and use of nephrotoxins. Conclusion. Overall, the incidence of AKI was low in our study sample with no statistically significant increased risk when PTZ was used in combination with vancomycin in a pediatric population. However, further investigation with an equal larger sample size is needed to confirm our findings.
\end{abstract}

\section{Background}

Vancomycin is a glycopeptide antibacterial drug that is commonly used in the hospital setting for treatment of grampositive infections and infections caused by methicillinresistant Staphylococcus aureus (MRSA) [1]. Piperacillintazobactam (PTZ) is a combination of piperacillin and the blactamase inhibitor tazobactam. Piperacillin-tazobactam has a broad-spectrum antibacterial activity that covers aerobic gram-positive, gram-negative, and anaerobic bacteria but does not cover MRSA [2,3].

Vancomycin and PTZ are commonly used as empirical therapy for patients with healthcare-associated infections as they are active against both methicillin-resistant Staphylococcus aureus (MRSA) and Pseudomonas aeruginosa [4]. Vancomycin has been recognized as a nephrotoxic agent, and in a few cases in the literature PTZ has been associated with interstitial nephritis [5-7].

In recent years, there have been some retrospective studies that showed high rates of acute kidney injury (AKI) in patients receiving vancomycin and piperacillin-tazobactam concomitant therapy which are higher than those reported for patients receiving vancomycin alone [8-12]. A retrospective cohort study at Duke University hospital reported a significantly lower incidence of AKI in patients receiving vancomycin $(8.1 \%)$ compared to those treated with vancomycin 
and PTZ (16.3\%) [8]. Another retrospective cohort study conducted at the University of Florida's Health Science Center found that the incidence of AKI was significantly higher in patients receiving PTZ with vancomycin (34.8\%) compared to patients receiving cefepime with vancomycin (12.5\%) [9].

Several other studies on different combination of medications showed that AKI rates were significantly higher in patients receiving vancomycin plus PTZ than vancomycin plus cefepime or other antibiotic medications [10-12]. In contrast, a number of studies reported similar AKI risk in these groups who received combination treatment [13, 14]. In summary, the incidence of AKI in adult patients receiving a combination of vancomycin and PTZ was relatively high, ranging from 15 to $38 \%[8-12,15,16]$, as the incidence of AKI and risk factors are not yet established well for pediatric patients, where only a few studies and case reports are available in the literature $[15,16]$. This research aimed to shed light on the incidence and risk factors of AKI in pediatric patients treated with vancomycin and PTZ compared to vancomycin alone or in combination with a cephalosporin that is commonly used in our hospital.

\section{Methods}

This is a single-center retrospective cohort study to evaluate the incidence and risk of AKI in pediatric patients treated with vancomycin with PTZ, ceftazidime, or ceftriaxone versus vancomycin monotherapy, at King Abdullah Children Specialized Hospital (KASCH) which is the first specialist children's hospital in the Kingdom of Saudi Arabia, occupying $192,000 \mathrm{~m}^{2}$, over 10 levels with a total bed capacity of 600 beds. The study period was from September 2015 to December 2016. Study participants were identified using our electronic health care system, to identify patients who were treated with vancomycin during the study period. AKI was defined using the Kidney Disease: Improving Global Outcomes (KDIGO) criteria; as an increase in serum creatinine (SCr) by $\geq 0.3 \mathrm{mg} / \mathrm{dl}$ ( $\geq 26.5 \mu \mathrm{mol} / \mathrm{l})$ within 48 hours; or as an increase in SCr level by $50 \%$ or higher from baseline. Inclusion criteria were patients aged one month to 14 years and had received vancomycin with $\mathrm{PTZ}$, ceftazidime or ceftriaxone concomitantly or vancomycin monotherapy for $\geq 48$ hours. Exclusion criteria were (A) patients currently on dialysis, having a history of chronic kidney disease (CKD) (stage III or higher) or structural kidney disease (e.g., one kidney, kidney transplant, kidney tumor); (B) diagnosis of kidney injury due to causes other than the therapy; (C) ICU patients; (D) receiving therapy less than 48 hours; (E) incomplete lab data (SCr); (F) receiving local routes of vancomycin like intraperitoneal, eye drops, or oral vancomycin; $(G)$ neonates less than 1 month old.

Pediatric patients admitted to KACSH wards and who met the above-specified inclusion and exclusion criteria were included.

The following patient demographic and clinical data were collected: age, height, weight, gender, dose of vancomycin, PTZ, ceftazidime and ceftriaxone, laboratory data (SCr and blood urea nitrogen), treatment indication, and initial vancomycin serum trough concentrations.

Statistical analysis: descriptive statistical analyses were performed for the study participants. Continuous variables were summarized using mean $\pm \mathrm{SD}$, median, and interquartile range (IQR). Proportions were used for categorical variables. The four medication groups were compared in terms of baseline demographic and clinical characteristics as well as incidence of AKI. Comparisons were made using the one-way ANOVA or Kruskal-Wallis test for continuous variables and the chi-square test for categorical variables. A logistic regression model was utilized to estimate and adjust odds ratio of AKI in the four groups. The model was adjusted for several baseline demographic and clinical characteristics. Statistical significance was considered at $\mathrm{p}<0.05$. All statistical analyses were performed using SPSS 21.0 [Release 21.0.0.0, IBM, USA].

\section{Results}

A total of 737 patients who received vancomycin during the study period were screened for inclusion in the study. A total of 248 met the specified inclusion criteria for our study. Descriptive statistics of the demographic and baseline characteristics of the patients are presented in Table 1. The number of patients in each treatment group was as follows: vancomycin alone 36 (14.5\%), vancomycin and PTZ $62(25.0 \%)$, vancomycin and ceftazidime 99 (39.9\%), and vancomycin and ceftriaxone 51 (20.6\%). Average \pm SD age was $5.3 \pm 3.4$ years with $54 \%$ males. Indications for treatment were documented to be empirical in $32 \%$, pneumonia $15 \%$, fever $13 \%$, URTI $9 \%$, sepsis $7 \%$, febrile neutropenia $4 \%$, meningitis $4 \%$, and $26 \%$ had other diagnoses. Underlying conditions of the patients were $12 \%$ congenital heart disease, $18.5 \%$ asthma, and $14.5 \%$ seizures. Around $30 \%$ of patients used other nephrotoxic medications. The average length of stay (LOC) before therapy was 6.7 days $(\mathrm{SD}=19.9)$.

The distribution of cultures is presented in Table 2. Only $84(34 \%)$ patients had a positive culture; the majority of them had Staphylococcus aureus, Pseudomonas aeruginosa, Klebsiella pneumonia, Candida albicans, or Escherichia coli.

Table 3 shows descriptive statistics for antibiotics (vancomycin, PTZ, ceftazidime, and ceftriaxone) dose and frequency as well as total days of therapy. The table also includes descriptive follow-up data. Descriptive statistics for outcomes (AKI and total LOS) are also provided in Table 4.

Results from comparing the four treatment groups are shown in Table 4.

There were no statistically significant differences between the four treatment groups in terms of AKI incidence, vancomycin trough, use of other nephrotoxins, or duration of therapy $(\mathrm{p}>0.05)$. As Table 4 illustrates, the treatment groups differed significantly in terms of vancomycin dose and total LOS. Patients receiving vancomycin plus PTZ or vancomycin plus ceftriaxone had a statistically significant higher vancomycin dose than those in the other two groups $(p=0.019)$. Although they seemed to have received higher doses of vancomycin than the other two groups, we did not 
TABLE 1: Profile of patients, baseline characteristics. $\mathrm{N}=248$.

\begin{tabular}{|c|c|c|c|}
\hline Factor & Number (\%) & Factor & $\begin{array}{c}\text { Mean } \pm \text { SD } \\
\text { Median (IQR) }\end{array}$ \\
\hline Gender & & Age (years) & $5.3 \pm 3.4$ \\
\hline Male & $134(54.0 \%)$ & & $5(2-7)$ \\
\hline Female & $114(46.0 \%)$ & & \\
\hline Treatment & & Weight (kg) & $18.0 \pm 12.3$ \\
\hline Vancomycin alone & $36(14.5 \%)$ & & $16.0(9.8-22.0)$ \\
\hline Vancomycin and PTZ & $62(25.0 \%)$ & & \\
\hline Vancomycin plus Ceftazidime & 99 (39.9\%) & & \\
\hline \multirow[t]{2}{*}{ Vancomycin plus Ceftriaxone } & $51(20.6 \%)$ & Height $(\mathrm{cm})$ & $100.1 \pm 28.0$ \\
\hline & & & $104(79-119)$ \\
\hline \multicolumn{4}{|l|}{ Indication of Antibiotics } \\
\hline Empirical & $79(31.9 \%)$ & Creatinine $(\mathrm{mg} / \mathrm{dL})$ & $0.45 \pm 0.1$ \\
\hline Pneumonia & $37(14.9 \%)$ & & $0.44(0.38-0.5)$ \\
\hline Fever & $33(13.3 \%)$ & & \\
\hline URTI & $23(9.3 \%)$ & & \\
\hline Sepsis & $17(6.9 \%)$ & BUN (mg/dL) & $10.1 \pm 5.3$ \\
\hline Other* & $59(23.7 \%)$ & & $8.7(6.2-13.7)$ \\
\hline \multicolumn{4}{|l|}{ Underlying conditions } \\
\hline$\overline{\text { History of G6PD deficiency }}$ & $6(2.4 \%)$ & $\mathrm{WBC}\left(\mathrm{x} 10^{9} / \mathrm{L}\right)$ & $10.9 \pm 7.3$ \\
\hline Trauma & $5(2.0 \%)$ & & $10.0(5.4-15.0)$ \\
\hline GERD & $14(5.6 \%)$ & & \\
\hline Cerebral Palsy & $9(3.6 \%)$ & LOS Before Therapy (days) & $6.7 \pm 19.9$ \\
\hline Sickle Cell Disease & $15(6.0 \%)$ & & $0(0-4)$ \\
\hline Congenital Heart Disease & $31(12.5 \%)$ & & \\
\hline Asthma & $46(18.5 \%)$ & & \\
\hline Seizures & $36(14.5 \%)$ & $\begin{array}{l}\text { Use of concomitant } \\
\text { nephrotoxins } * *\end{array}$ & $76(30.6 \%)$ \\
\hline Diabetes & $2(0.8 \%)$ & & \\
\hline History of Malignancy & $20(8.1 \%)$ & & \\
\hline
\end{tabular}

* Other: febrile neutropenia, meningitis, UTI, bacteremia, skin infection, and trauma.

** Aminoglycoside, furosemide, amphotericin B, colistin, ACEIs, ARBs, NSAID, tacrolimus, acyclovir, and cyclosporine.

URTI: upper respiratory tract infection, G5PD: Glucose-6-Phosphate Dehydrogenase, GERD: gastroesophageal reflux disease, BUN: blood urea nitrogen, and LOS: length of stay.

TABLE 2: Culture distribution. $\mathrm{N}=248$.

\begin{tabular}{lcc}
\hline Type & N & Percent \\
\hline Staphylococcus aureus & 22 & $8.9 \%$ \\
Pseudomonas aeruginosa & 13 & $5.2 \%$ \\
Klebsiella pneumoniae & 9 & $3.6 \%$ \\
Candida albicans & 6 & $2.4 \%$ \\
Escherichia coli & 5 & $2.0 \%$ \\
MRSA & 4 & $1.6 \%$ \\
Other & 25 & $10.1 \%$ \\
None & 164 & $66.2 \%$ \\
\hline
\end{tabular}

Other: Acinetobacter baumannii, S. pneumoniae, Viridans streptococci, Staphylococcus epidermidis, Haemophilus influenzae, Candida parapsilosis, Enterococcus faecalis, Enterococcus faecium, Enterobacter asburiae, Enterobacter cloacae, HSV, Influenza virus B, RSV, Serratia plymuthica, Shigella flexneri. 
TABLE 3: Doses, frequency, and follow-up measures.

\begin{tabular}{|c|c|c|}
\hline Factor & & \\
\hline \multirow[t]{2}{*}{ Vancomycin dose (mg/kg/day) } & Mean \pm SD & $45.8 \pm 14.1$ \\
\hline & Median (IQR) & $45.0(38.0-58.0)$ \\
\hline \multicolumn{3}{|l|}{ Vancomycin frequency $\mathrm{n}(\%)$} \\
\hline Every 6 hours & & $172(69.4 \%)$ \\
\hline Every 8 hours & & $70(28.2 \%)$ \\
\hline Every 12 hours & & $4(1.6 \%)$ \\
\hline Every 24 hours & & $2(0.8 \%)$ \\
\hline \multirow[t]{2}{*}{ Initial vancomycin trough level $(\mathrm{mg} / \mathrm{L})$} & Mean \pm SD & $9 \pm 5.2$ \\
\hline & Median (IQR) & $8.1(4.9-11.7)$ \\
\hline \multirow[t]{2}{*}{ Piperacillin-tazobactam dose (mg/kg/dose) } & Mean \pm SD & $95.8 \pm 24.5$ \\
\hline & Median (IQR) & $100.0(89.5-100.0)$ \\
\hline \multicolumn{3}{|l|}{ Piperacillin-tazobactam frequency $\mathrm{n}(\%)$} \\
\hline Every 6 hours & & $5(8.1 \%)$ \\
\hline Every 8 hours & & $57(91.9 \%)$ \\
\hline \multirow[t]{2}{*}{ Ceftazidime dose (mg/kg/dose) } & Mean \pm SD & $45.8 \pm 9.2$ \\
\hline & Median (IQR) & $50.0(49.0-50.0)$ \\
\hline \multicolumn{3}{|l|}{ Ceftazidime frequency $\mathrm{n}(\%)$} \\
\hline Every 8 hours & & $99(100 \%)$ \\
\hline \multirow[t]{2}{*}{ Ceftriaxone dose (mg/kg/dose) } & Mean \pm SD & $61.2 \pm 31.0$ \\
\hline & Median (IQR) & $50.0(45.0-71.3)$ \\
\hline \multicolumn{3}{|l|}{ Ceftriaxone frequency $\mathrm{n}(\%)$} \\
\hline Every 12 hours & & $10(19.6 \%)$ \\
\hline Every 24 hours & & $41(80.4 \%)$ \\
\hline \multirow[t]{2}{*}{ WBC $\left(\times 10^{9} / \mathrm{L}\right) 48$ hours } & Mean \pm SD & $8.5 \pm 5.2$ \\
\hline & Median (IQR) & $8.0(5.0-11.4)$ \\
\hline \multirow[t]{2}{*}{ Days of therapy } & Mean \pm SD & $7.2 \pm 7.2$ \\
\hline & Median (IQR) & $5.0(4.0-8.0)$ \\
\hline
\end{tabular}

TABLE 4: Outcomes (AKI and LOS) and use of concomitant nephrotoxins, vancomycin trough, daily vancomycin dose, and duration of therapy in overall and by treatment. $\mathrm{N}=248$.

\begin{tabular}{|c|c|c|c|c|c|}
\hline \multicolumn{6}{|c|}{ Groups } \\
\hline Factor & $\begin{array}{c}\text { All } \\
\text { Patients } \\
(n=248)\end{array}$ & $\begin{array}{l}\text { Vancomycin } \\
\qquad(\mathrm{n}=36)\end{array}$ & $\begin{array}{c}\text { Vancomycin } \\
+ \\
\text { PTZ } \\
(\mathrm{n}=62)\end{array}$ & $\begin{array}{c}\text { Vancomycin } \\
+ \\
\text { Ceftazidime } \\
(\mathrm{n}=99)\end{array}$ & $\begin{array}{c}\text { Vancomycin } \\
+ \\
\text { Ceftriaxone } \\
(\mathrm{n}=51)\end{array}$ \\
\hline AKI cases & $4(1.6 \%)$ & $0(0.0 \%)$ & $3(4.8 \%)$ & $0(0.0 \%)$ & $1(2.0 \%)$ \\
\hline $\begin{array}{l}\text { Use of concomitant nephrotoxic } \\
\text { medication }\end{array}$ & $76(30.6 \%)$ & $10(27.8 \%)$ & $21(33.9 \%)$ & $33(33.3 \%)$ & $12(23.5 \%)$ \\
\hline \multicolumn{6}{|l|}{ Duration of therapy (days) } \\
\hline Mean \pm SD & $7.2 \pm 7.2$ & $9.1 \pm 13.9$ & $7.1 \pm 4.9$ & $7.4 \pm 5.9$ & $5.8 \pm 4.5$ \\
\hline Median (IQR) & $5.0(4.0-8.0)$ & $5.0(4.0-6.0)$ & $5.0(4.0-9.0)$ & $6.0(4.0-8.0)$ & $5.0(4.0-7.0)$ \\
\hline \multicolumn{6}{|c|}{ Initial vancomycin trough level $(\mathrm{mg} / \mathrm{L})$} \\
\hline Mean \pm SD & $9 \pm 5.2$ & $9 \pm 4.9$ & $9 \pm 5.5$ & $8.7 \pm 5.2$ & $9.3 \pm 5.2$ \\
\hline \multicolumn{6}{|l|}{ Daily vancomycin dose (mg/kg/day) } \\
\hline Mean \pm SD & $45.8 \pm 14.1$ & $44.2 \pm 14.3$ & $49.2 \pm 13.7$ & $43 \pm 13.4$ & $48.5 \pm 14.7 *$ \\
\hline \multicolumn{6}{|l|}{ Total LOS (days) } \\
\hline Mean \pm SD & $24.7 \pm 37.5$ & $13.0 \pm 13.5$ & $41.8 \pm 49.2$ & $25.6 \pm 39.8$ & $10.3 \pm 9.2 *$ \\
\hline Median (IQR) & $11.0(7.0-21.8)$ & $8.5(6.0-14.0)$ & $19.5(10.0-60.0)$ & $12.0(8.0-21.0)$ & $7.0(6.0-12.0)$ \\
\hline
\end{tabular}

$*$ Difference is highly significant $(\mathrm{p}<0.001)$. 
TABLE 5: Cases of acute kidney injury.

\begin{tabular}{|c|c|c|c|c|c|c|c|c|}
\hline Case & $\begin{array}{l}\text { Treatment } \\
\text { Regimen }\end{array}$ & Age & Gender & $\begin{array}{c}\text { Dose of } \\
\text { vancomycin } \\
(\mathrm{mg} / \mathrm{kg} / \text { day })\end{array}$ & Frequency & Trough $(\mathrm{mg} / \mathrm{L})$ & Duration of treatment & $\begin{array}{c}\text { Use of concomitant } \\
\text { nephrotoxic } \\
\text { medication }\end{array}$ \\
\hline 1 & $\begin{array}{c}\text { Vancomycin and } \\
\text { PTZ }\end{array}$ & 14 & M & 50 & Every 6 hours & 8 & 23 days & $\begin{array}{c}\text { Yes } \\
\text { (gentamicin) }\end{array}$ \\
\hline 2 & $\begin{array}{c}\text { Vancomycin and } \\
\text { PTZ }\end{array}$ & 7 & $\mathrm{~F}$ & 60 & Every 6 hours & No Trough & 5 days & $\begin{array}{c}\text { Yes } \\
\text { (Acyclovir) }\end{array}$ \\
\hline 3 & $\begin{array}{c}\text { Vancomycin and } \\
\text { PTZ }\end{array}$ & 6 & M & 60 & Every 8 hours & 11.6 & 9 days & No \\
\hline 4 & $\begin{array}{c}\text { Vancomycin and } \\
\text { Ceftriaxone }\end{array}$ & 13 & $\mathrm{~F}$ & 75 & Every 8 hours & 27.5 & 5 days & No \\
\hline
\end{tabular}

see an increased risk of AKI in those groups of patients. Also, patients in the vancomycin plus PTZ group had the longest LOS. So, despite higher doses and longest LOS, no significant increased risk was seen.

\section{Discussion}

Vancomycin is used usually concomitantly with other antibacterial drugs like beta-lactams; in recent years there have been some retrospectives studies indicating that using vancomycin with PTZ is associated with an increased risk of nephrotoxicity compared to vancomycin alone or vancomycin with other beta-lactams [8-12]. Most of these studies were conducted in adults while only a few studies and case reports were conducted in pediatric patients.

In general, there are many factors that might increase the risk of nephrotoxicity in patients receiving vancomycin plus PTZ beside the concomitant use of this combination, such as higher doses of vancomycin or PTZ, a high vancomycin trough level, and/or concomitant use of other nephrotoxic medications [8, 17-19].

PTZ in combination with vancomycin tends to be a more likely treatment selection in sicker patients as seen in our study where a significantly higher LOC was seen in this combination group. In our study, the overall incidence of AKI was low (1.4\%), 4 cases, where 3 cases (4.8\%) occurred in the vancomycin plus PTZ group and one case in the vancomycin plus ceftriaxone group, and no cases of AKI were seen in the vancomycin monotherapy or vancomycin plus ceftazidime groups. Nevertheless, the difference between the four groups in AKI incidence, vancomycin trough, use of other nephrotoxic drugs, or duration of therapy did not reach a statistical significance. It is worth noting that there was no increased risk of AKI in the vancomycin plus PTZ combination group despite statistically significantly higher doses of vancomycin used in this group.

Table 5 shows further assessment of the AKI cases revealed that two of the three patients with nephrotoxicity in the vancomycin plus PTZ group were on other nephrotoxic medications (i.e., gentamicin, acyclovir). And that the only case that occurred in a patient who received vancomycin and ceftriaxone had an elevated serum vancomycin trough $(27.5 \mathrm{mg} / \mathrm{L})$. Therefore, our findings confirm the notion that the increased risk of AKI is multifactorial rather than a risk solely associated with the use of this combination and that the concern of AKI possibly not on the top of the list when weighing the benefit versus the risk in the decision of selecting this combination.

In comparison, in our study the incidence of AKI was lower than that reported in other studies. In a study conducted at a single center by McQueen, AKI developed in 3 of 79 patients in the vancomycin group alone and in 25 of 106 patients on vancomycin plus PTZ and they include patients with underlying renal dysfunction in their study unlike ours [20], while on other larger retrospective multicenter study released this year by Downes, the incidence of AKI among those who received vancomycin plus PTZ combination therapy was 117 of 1009 patients (11.7\%) and 40 of $906(4.4 \%)$ in patients who received vancomycin plus other beta-lactam (ceftazidime, cefepime, and meropenem/imipenem) [21].

Our KASCH clinical pharmacy team preforms daily rounds and provides therapeutic drug monitoring (TDM) services for all our pediatric patients, good TDM has been linked to better patient outcome and a reduction in incidents of nephrotoxicity related to vancomycin, and our results applaud on their efforts and reflect their vigilance in monitoring our patients [22-24].

Finally, our study has several limitations that must be addressed. The study was retrospective and had a small sample size. An equal larger sample size is needed to confirm our findings.

\section{Conclusion}

Based on our study, the incidence of AKI was low in our study sample with no statistically significant increased risk when PTZ was used in combination with vancomycin in pediatric population. However, further investigation with an equal larger sample size is needed to confirm our findings.

\section{Abbreviations}

PTZ: Vancomycin and piperacillin-tazobactam AKI: Acute kidney injury

MRSA: Methicillin-resistant Staphylococcus aureus KASCH: King Abdullah Children Specialized Hospital KDIGO: Kidney Disease: Improving Global Outcomes SCr: $\quad$ Serum creatinine 
URTI: Upper respiratory tract infection

G5PD: Glucose-6-Phosphate Dehydrogenase

GERD: Gastroesophageal reflux disease

BUN: Blood urea nitrogen

LOS: Length of stay.

\section{Data Availability}

The data used to support the findings of this study are restricted by the KAIMRC in order to protect patient privacy. Data are available from KAIMRC for researchers who meet the criteria for access to confidential data.

\section{Ethical Approval}

The study was approved by the Institutional Review Board (IRB) of King Abdulaziz International Medical Research Center (KAIMRC), National Guard Health Affairs, Riyadh, Saudi Arabia, in February 2017.

\section{Conflicts of Interest}

The authors declare that they have no conflicts of interest.

\section{Authors' Contributions}

Mohammed Al Nuhait and Laila C. Abu Esba have written the paper; Laila C. Abu Esba has supervised the research; Rami T. Bustami and Mohammed Al Nuhait have analyzed and interpreted the data; Mohammed Al Nuhait, Meshary $\mathrm{Al}$ Meshary, and Khalid Al Harbi have worked on data collection and coordinated the study. Each author listed on the manuscript has seen and approved the submission of the present version of the manuscript and takes full responsibility for the manuscript.

\section{References}

[1] M. A. Cataldo, E. Tacconelli, E. Grilli, F. Pea, and N. Petrosillo, "Continuous versus intermittent infusion of vancomycin for the treatment of gram-positive infections: Systematic review and meta-analysis," Journal of Antimicrobial Chemotherapy, vol. 67, no. 1, pp. 17-24, 2012.

[2] S. Hussain, S. Syed, and K. Baloch, "Electrolytes imbalance: A rare side effect of piperacillin/tazobactam therapy," Journal of the College of Physicians and Surgeons Pakistan, vol. 20, no. 6, pp. 419-420, 2010.

[3] J. E. Bennett, R. Dolin, and M. J. Blaser, Principles and Practice of Infectious Diseases, vol. 28, Elsevier Health Sciences, 2014.

[4] S. S. Magill, J. R. Edwards, Z. G. Beldavs et al., "Prevalence of antimicrobial use in us acute care hospitals, may-september 2011," Journal of the American Medical Association, vol. 312, no. 14, pp. 1438-1446, 2014.

[5] T. J. Liu and J. P. Lam, "Piperacillin-tazobactam-induced acute interstitial nephritis with possible meropenem cross-sensitivity in a patient with osteomyelitis," American Journal of HealthSystem Pharmacy, vol. 69, no. 13, p. 1109, 2012.

[6] T. P. Lodise, N. Patel, B. M. Lomaestro, K. A. Rodvold, and G. L. Drusano, "Relationship between initial vancomycin concentration-time profile and nephrotoxicity among hospitalized patients," Clinical Infectious Diseases, vol. 49, no. 4, pp. 507514, 2009.

[7] J. A. Bosso, J. Nappi, C. Rudisill et al., "Relationship between vancomycin trough concentrations and nephrotoxicity: A prospective multicenter trial," Antimicrobial Agents and Chemotherapy, vol. 55, no. 12, pp. 5475-5479, 2011.

[8] L. D. Burgess and R. H. Drew, "Comparison of the incidence of vancomycin-induced nephrotoxicity in hospitalized patients with and without concomitant piperacillin-tazobactam," Pharmacotherapy, vol. 34, no. 7, pp. 670-676, 2014.

[9] D. M. Gomes, C. Smotherman, A. Birch et al., "Comparison of acute kidney injury during treatment with vancomycin in combination with piperacillin-tazobactam or cefepime," Pharmacotherapy, vol. 34, no. 7, pp. 662-669, 2014.

[10] B. Navalkele, J. M. Pogue, S. Karino et al., "Risk of acute kidney injury in patients on concomitant vancomycin and piperacillintazobactam compared to those on vancomycin and cefepime," Clinical Infectious Diseases, vol. 64, no. 2, pp. 116-123, 2017.

[11] V. Peyko, S. Smalley, and H. Cohen, "Prospective comparison of acute kidney injury during treatment with the combination of piperacillin-Tazobactam and vancomycin versus the combination of cefepime or meropenem and vancomycin," Journal of Pharmacy Practice, vol. 30, no. 2, pp. 209-213, 2017.

[12] S. Karino, K. S. Kaye, B. Navalkele et al., "Epidemiology of acute kidney injury among patients receiving concomitant vancomycin and piperacillin-tazobactam: Opportunities for antimicrobial stewardship," Antimicrobial Agents and Chemotherapy, vol. 60, no. 6, pp. 3743-3750, 2016.

[13] R. P. Moenster, T. W. Linneman, P. M. Finnegan, S. Hand, Z. Thomas, and J. R. McDonald, "Acute renal failure associated with vancomycin and $\beta$-lactams for the treatment of osteomyelitis in diabetics: piperacillin-tazobactam as compared with cefepime," Clinical Microbiology and Infection, vol. 20, no. 6, pp. O384-O389, 2014.

[14] D. A. Hammond, M. N. Smith, J. T. Painter, N. K. Meena, and K. Lusardi, "Comparative incidence of acute kidney injury in critically ill patients receiving vancomycin with concomitant piperacillin-tazobactam or cefepime: a retrospective cohort study," Pharmacotherapy, vol. 36, no. 5, pp. 463-471, 2016.

[15] J. A. Pratt, M. K. Stricherz, P. S. Verghese, and M. J. Burke, "Suspected piperacillin-tazobactam induced nephrotoxicity in the pediatric oncology population," Pediatric Blood \& Cancer, vol. 61, no. 2, pp. 366-368, 2014.

[16] B. W. Ibach, E. D. Henry, and P. N. Johnson, "Acute kidney injury in a child receiving vancomycin and piperacillin/tazobactam," The Journal of Pediatric Pharmacology and Therapeutics, vol. 21, no. 2, pp. 169-175, 2016.

[17] S. McKamy, E. Hernandez, M. Jahng, T. Moriwaki, A. Deveikis, and J. Le, "Incidence and risk factors influencing the development of vancomycin nephrotoxicity in children," Journal of Pediatrics, vol. 158, no. 3, pp. 422-426, 2011.

[18] J. Le, P. Ny, E. Capparelli et al., "Pharmacodynamic characteristics of nephrotoxicity associated with vancomycin use in children," Journal of the Pediatric Infectious Diseases Society, vol. 4, no. 4, pp. e109-e116, 2015.

[19] C. A. Knoderer, K. R. Nichols, K. C. Lyon, M. M. Veverka, and A. C. Wilson, "Are elevated vancomycin serum trough concentrations achievedwithin the first 7 days of therapy associatedwith acute kidney injury in children?" Journal of the Pediatric Infectious Diseases Society, vol. 3, no. 2, pp. 127-131, 2014. 
[20] K. E. McQueen and D. W. Clark, "Does Combination Therapy With Vancomycin and Piperacillin-Tazobactam Increase the Risk of Nephrotoxicity Versus Vancomycin Alone in Pediatric Patients?" The Journal of Pediatric Pharmacology and Therapeutics, vol. 21, no. 4, pp. 332-338, 2016.

[21] K. J. Downes, C. Cowden, B. L. Laskin et al., "Association of acute kidney injury with concomitant vancomycin and piperacillin/tazobactam treatment among hospitalized children," JAMA Pediatrics, vol. 171, no. 12, 2017.

[22] H. T. Masoumi, M. Khataminia, and M. Hadjibabaie, "PS035 Evaluation of pharmacist intervention on vancomycin dosing and nephrotoxicity prevention," in Proceedings of the 22nd EAHP Congress 22-24 March 2017 Cannes, France, pp. A242.2A242, 2017.

[23] K. A. Marquis, J. R. DeGrado, S. Labonville, D. W. Kubiak, and P. M. Szumita, "Evaluation of a pharmacist-directed vancomycin dosing and monitoring pilot program at a tertiary academic medical center," Annals of Pharmacotherapy, vol. 49, no. 9, pp. 1009-1014, 2015.

[24] A. P. Smith, C. A. Millares-Sipin, M. James, and H. Cohen, "Impact of a pharmacist-initiated vancomycin monitoring program," Consultant Pharmacist, vol. 31, no. 9, pp. 505-510, 2016. 


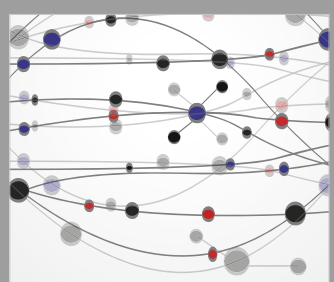

The Scientific World Journal
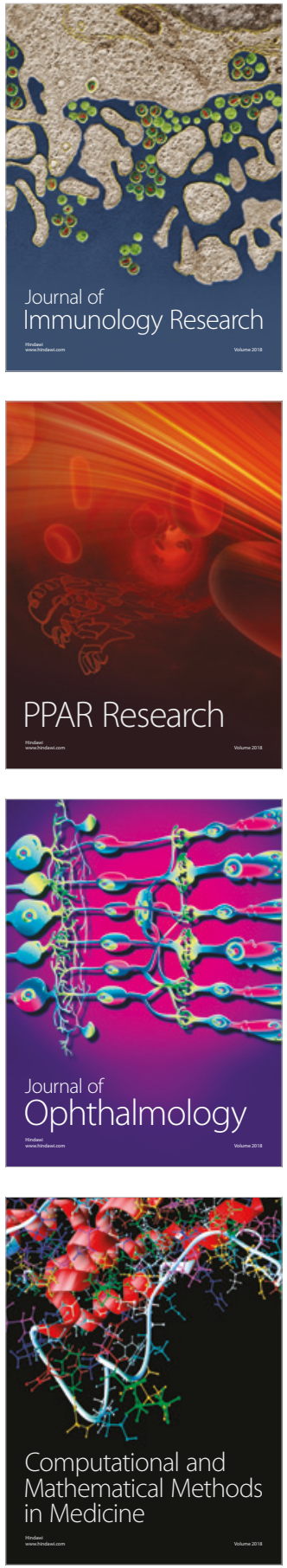

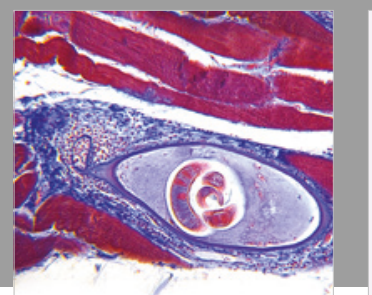

Gastroenterology Research and Practice

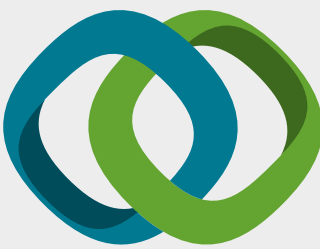

\section{Hindawi}

Submit your manuscripts at

www.hindawi.com
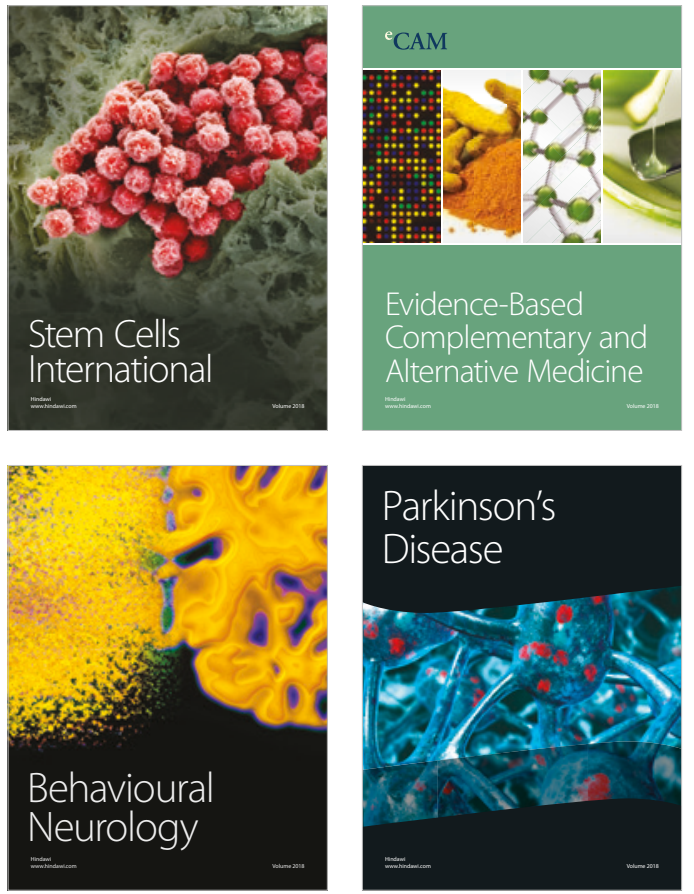

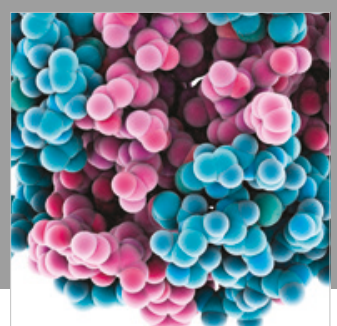

ournal of

Diabetes Research

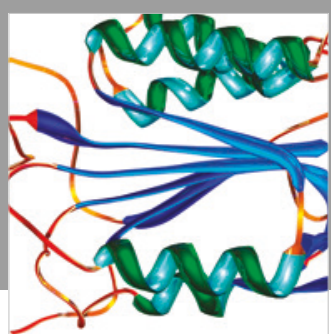

Disease Markers
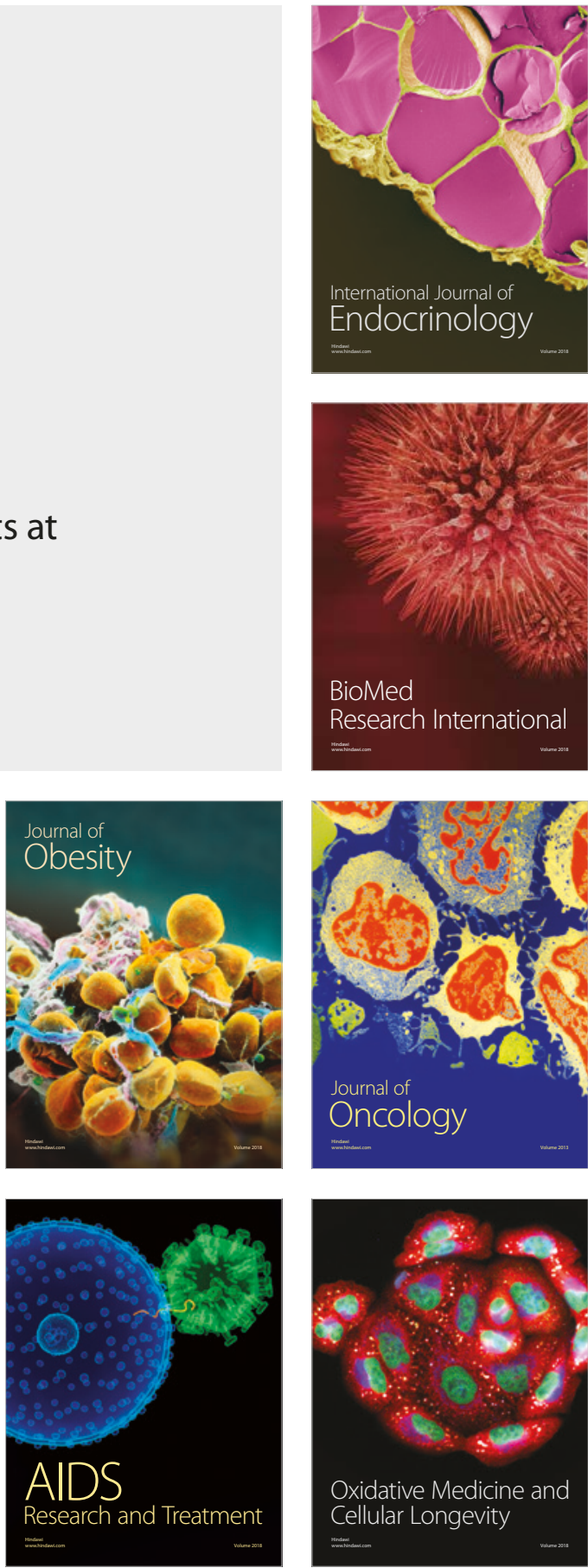